\title{
The impact of patient characteristics on enzalutamide pharmacokinetics and how this relates to treatment toxicity and efficacy in metastatic prostate cancer patients
}

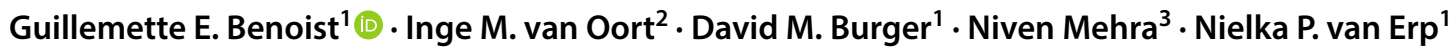

Received: 20 October 2019 / Accepted: 31 January 2020 / Published online: 19 February 2020

(c) The Author(s) 2020

\begin{abstract}
Purpose The aim of the study is to investigate the influence of patient characteristics, age and body mass index (BMI), on pharmacokinetics of enzalutamide, and to study the relationships between drug exposure and enzalutamide efficacy and toxicity, in mCRPC patients.

Methods Data were collected in a longitudinal cohort study (ANDROPS) and a prospective observational study (ILUMINATE), both in mCRPC patients treated with enzalutamide. To investigate the influence of age and BMI on exposure, enzalutamide and N-desmethylenzalutamide levels were compared by ANOVA. To investigate the relation of exposure versus time to progression (TTP), the sum plasma levels were divided into quartiles and compared by Kaplan-Meier analysis. To assess the relation of exposure with fatigue, plasma levels in patients experiencing fatigue vs. no fatigue were compared by and independent $t$ test.

Results Data of $68 \mathrm{mCRPC}$ patients were included for analysis. Plasma levels were not different for age or BMI. No difference in TTP between both studies was observed (383 days (95\% CI 287-859), and 567 days (95\% CI 351-NR), $p=0.36$ ). Kaplan-Meier analysis of quartiles of sum levels showed no difference for TTP. Fatigue was reported by 22 patients, no difference in sum plasma levels was observed between patients with and without fatigue.

Conclusions We observed that age and BMI did not influence systemic exposure in patients treated with enzalutamide. No relation of exposure with efficacy or fatigue was observed. Further research using enzalutamide at a lower dose is needed to understand the relation of enzalutamide exposure and fatigue.
\end{abstract}

Keywords Enzalutamide $\cdot$ Fatigue $\cdot$ Pharmacokinetics $\cdot$ Metastatic castration-resistant prostate cancer

\section{Introduction}

Metastatic castration-resistant prostate cancer (mCRPC) is the second most common cancer in men in western countries [1]. Currently, the median overall survival for mCRPC patients is varying between 19 and 35 months [2,3]. Prior to

Guillemette E. Benoist

mette.benoist@radboudumc.nl

1 Department of Pharmacy, Radboud University Medical Center, Radboud Institute for Health Sciences, Nijmegen, The Netherlands

2 Department of Urology, Radboud University Medical Center, Nijmegen, The Netherlands

3 Department of Medical Oncology, Radboud University Medical Center, Nijmegen, The Netherlands
2011, docetaxel was the only therapy available, but during the last decade, multiple life-prolonging therapies became available: e.g. cabazitaxel, radium-223, and two oral antiandrogen directed therapies, abiraterone acetate and enzalutamide [4-7]. Recently, the indication for enzalutamide treatment was broadened from metastatic to non-metastatic CRPC $[8,9]$. Furthermore, enzalutamide showed improved overall survival in the hormone-sensitive setting which may broaden the patient population even more in the nearby future [10].

During ageing, several factors that may affect the pharmacokinetics of enzalutamide change, for example an increase in body fat and decrease in clearance of the liver with older age [11]. Furthermore, in the population pharmacokinetic analysis, enzalutamide exposure was $\sim 20 \%$ lower in mCRPC patients with a higher weight ( $120 \mathrm{~kg}$ vs. $70 \mathrm{~kg})$, this may be attributed to an increased volume of distribution. Finally, it 
was shown that CRPC patients treated outside of clinical trials had different baseline characteristics compared to study patients, which may be of influence on the pharmacokinetics of enzalutamide and its active metabolite [12].

However, limited data are available on the relation between enzalutamide and $\mathrm{N}$-desmethylenzalutamide exposure and patient characteristics. Only one pharmacokinetic study, outside the registration study, of enzalutamide in relation to patient characteristics is currently available, showing that age did not affect enzalutamide exposure [13]. The population pharmacokinetic analysis did not reveal an exposure response relationship for overall survival also no consistent relation was found for exposure and toxicity.

One of the most commonly reported side effects of enzalutamide is fatigue, occurring in approximately $36 \%$ of the patients during the PREVAIL trial [3]. The hypothesis is that fatigue might be caused by the exposure to both enzalutamide and its active metabolite N-desmethylenzalutamide. Both cross the blood-brain barrier and have high affinity for the GABA receptor. This has previously been described in mice and rats for enzalutamide and N-desmethylenzalutamide as well as for other anti-androgens, such as nilutamide and flutamide $[9,14]$. While fatigue was a dose-dependent adverse event in the phase I study, no consistent relationship between enzalutamide plasma concentrations and fatigue was found in the pharmacometric analysis $[15,16]$.

Eliasson et al. showed that patients with advanced prostate cancer prefer a therapy that (1) controls bone pain, (2) delays chemotherapy, (3) avoids side effects such as memory loss and extreme tiredness. This patient preference underlines the significance of understanding the potential relation between systemic exposure to enzalutamide plus N-desmethylenzalutamide and fatigue. This will help to improve and potentially even prevent central nervous system toxicity of this therapy for future patients [17].

In summary, by an improved understanding of the effect of patient characteristics on the pharmacokinetics, and the relationship of exposure with efficacy and toxicity, treatment with enzalutamide might in the future be individualised.

\section{Materials and methods}

For this analysis, data of two studies were used. ANDROPS was a longitudinal observational cohort study in patients treated with $160 \mathrm{mg}$ enzalutamide once daily, in the Radboud university medical center (Nijmegen, the Netherlands). Patients were included from September 2015 to February 2019 while on treatment or starting treatment with enzalutamide.

ILUMINATE was a multi-center prospective study in patients with mCRPC who started treatment with enzalutamide (ClinicalTrials.gov NCT02471469). Patients were included from July 2015 to September 2017 in five hospitals in the Netherlands (Canisius Wilhelmina Hospital, Gelderse Vallei hospital, Francisus gasthuis and Vlietland hospital, Reinier de Graaf Hospital, Radboud university medical center). Patients who did not receive prior chemotherapy and patients who had upfront docetaxel according to CHAARTED/STAMPEDE trial protocols were eligible for this study.

After informed consent, blood was drawn at standard patient visits in the outpatient clinic at random times in the ANDROPS study and at prespecified moments in the ILUMINATE study (pre-dose after 1, 3 and 6 months of enzalutamide treatment). Each blood sample was collected into an ethylenediaminetetraacetic acid containing tube, and for quantification of enzalutamide and N-desmethylenzalutamide concentrations, a validated method as previously described was used [18]. Due to the long half-life of enzalutamide (mean 5.8 days) and its active metabolite (mean 8.6 days), there is a small difference between the maximum and minimum concentrations of enzalutamide and $\mathrm{N}$-desmethylenzalutamide (ratio of 1.25 for enzalutamide), allowing random time of sampling.

Only pharmacokinetic results at steady state ( $>40$ days) and during the first 6 months of treatment, at a dose $160 \mathrm{mg}$, and $>1 \mathrm{~h}$ after intake were included for analysis. Fatigue data (yes/no) and data on radiological or biochemical progression were retrospectively collected from the electronic medical record (ANDROPS) or case report form (ILUMINATE). Exclusion criteria for analysis of toxicity were: clinical anemia $(\mathrm{Hb}<5.6 \mathrm{mmol} / \mathrm{L})$ and concomitant use of stimulants (e.g. methylphenidate). Both ANDROPS and ILUMINATE were approved by the institutional ethical board. In Fig. 1, an overview of the two studies is shown.

To compare data of both studies, geometric mean levels were compared by independent $t$ test. And to compare time to progression, Kaplan-Meier analysis was performed. When no difference between the two studies was shown, data were pooled for further analysis.

Pharmacokinetic variability within patients was described for the data collected in the ILUMINATE study. To explore the relation of exposure with age (in tertiles) and groups of BMI, geometric mean levels of these groups were compared by analysis of variance (ANOVA).To evaluate the relation of exposure and efficacy, sum of enzalutamide and $\mathrm{N}$-desmethylenzalutamide levels were divided in quartiles and analyzed in relation to time to progression by Kaplan-Meier (KM) curves, and differences between the KM curves were tested for significance by the log-rank test. Finally, to evaluate the prevalence of fatigue in relation to drug exposure, the geometric mean levels of patients with event (fatigue) were compared to the levels of patients without fatigue, by an independent $t$ test. PSA response was compared between 
Fig. 1 Overview of the ILUMINATE and ANDROPS study

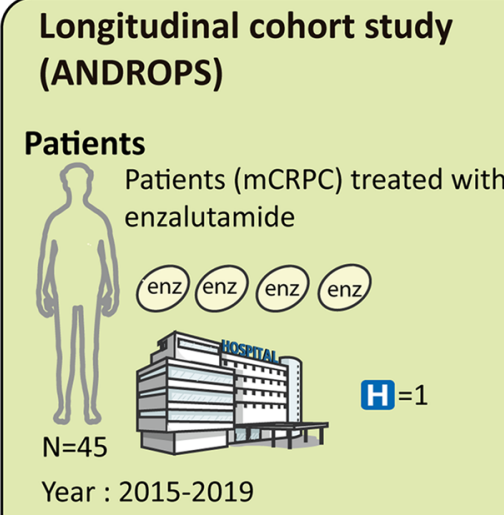

previous anti-cancer therapies: no restrictions
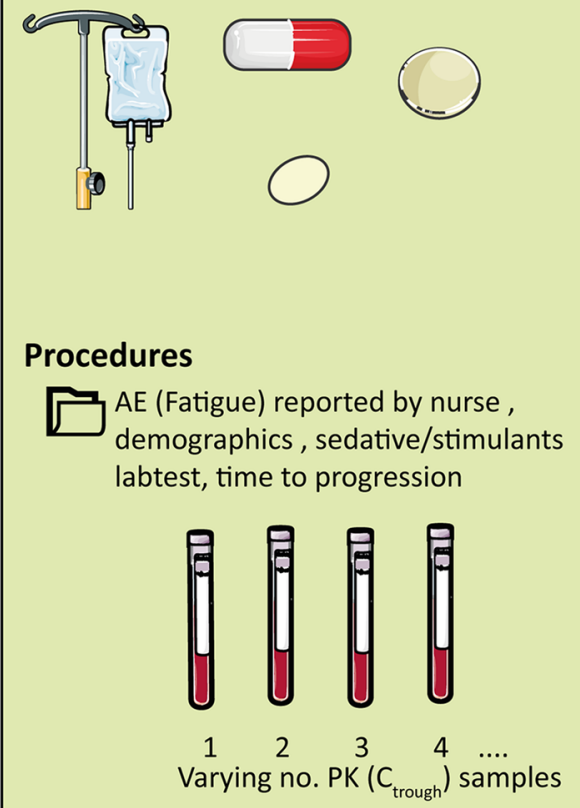

\section{ILUMINATE study}

\section{Patients}

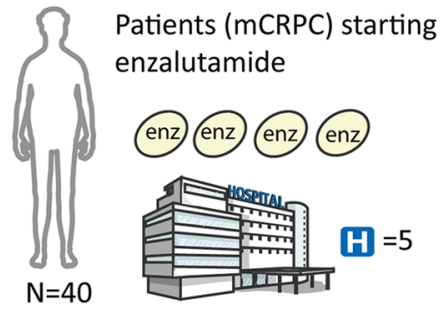

Year: 2016-2018

chemotherapy-naive, no previous treatments

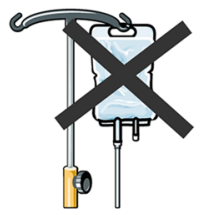

\section{Procedures}

patient reported AEs demographics, sedative/stimulants
labtest, time to progression

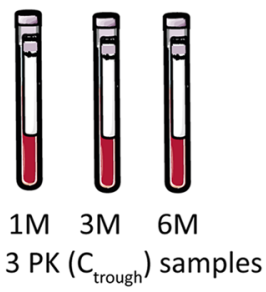

Data Demographic data were compared Pharmacokinetic data were pooled for time-to-event analysis and for analysis of patient characteristics (age/weight)

Exploratory analysis of PK-toxicity relation was validated with data from ILUMINATE

the two groups (fatigue and no fatigue) to monitor if PSA response was of influence on fatigue.

\section{Results}

Between 2014 and 2019, 46 mCRPC patients were included in the ANDROPS study and 40 patients in ILUMINATE. In six patients, the dose was reduced to 120 or $80 \mathrm{mg}$ enzalutamide based on tolerability ( $n=3$ ANDROPS, $n=3$ ILUMINATE). For 68 patients (29 ANDROPS/ 39 ILUMINATE) out of the total number (86) of included patients, samples at steady state were available within 6 months from start and results were used for the following analysis. Baseline characteristics for these patients are described in Table 1.

No statistical difference was observed between geometric mean levels (CV\%) of enzalutamide in ANDROPS vs ILUMINATE (12.3 mg/L (20) vs. $13 \mathrm{mg} / \mathrm{L}$ (21.2), $p=0.26)$ and $\mathrm{N}$-desmethylenzalutamide (12.9 mg/L (30.1) vs. $13.7 \mathrm{mg} / \mathrm{L}(23.2), p=0.41)$. Time to progression was not different between the two studies: in the ANDROPS, study median TTP was 383 days (95\% CI 287-859) and in ILUMINATE, the TTP was 567 days (95\% CI 351-NR) $p=0.36$, Fig. 2a. The geometric mean levels (CV\%) for the sum (enzalutamide $+\mathrm{N}$-desmethylenzalutamide), enzalutamide alone and $\mathrm{N}$-desmethylenzalutamide alone, were $26.0 \mathrm{mg} / \mathrm{L}$ (16.4), $12.6 \mathrm{mg} / \mathrm{L} \mathrm{(20.6)} \mathrm{and} 13.6 \mathrm{mg} / \mathrm{L}$ 
Table 1 Patient characteristics at baseline

\begin{tabular}{llll}
\hline & ANDROPS $(N=29)$ & ILUMINATE $(N=39)$ & Overall $(N=68)$ \\
\hline Age (years) & $70(14)$ & $74(8)$ & $72(9)$ \\
Weight $(\mathrm{kg})$ & $87(12)$ & $85(13)$ & $85(13)$ \\
BMI $\left(\mathrm{kg} / \mathrm{m}^{2}\right)$ & $26.5(4.5)$ & $28.1(4.5)$ & $26.5(4.2)$ \\
PSA level $(\mathrm{ng} / \mathrm{mL})$ & $40(49)$ & $49(72)$ & $43(71)$ \\
PSA doubling time (months) & $2.8(2.9)$ & $4.1(4.1)$ & $3.4(3.3)$ \\
Gleason score $\leq 8$ & $55.6 \%$ & $48.7 \%$ & $50 \%$ \\
Gleason score $>8$ & $44.4 \%$ & $51.3 \%$ & $50 \%$ \\
Hb level (mmol/L) & $8(1.1)$ & $8(0.9)$ & $8.1(1)$ \\
Albumin (g/L) & $36(4)$ & $41(6)$ & $38(5.5)$ \\
LDH (U/L) & Not collected & $228(70)$ & - \\
WHO Performance score & & & - \\
0 & Not collected & 71.8 & $22.1(15)$ \\
$\geq 1$ & Not collected & 28.2 & $2.9(2)$ \\
Chemotherapy $(\%)$ & 41.4 & 7.7 & \\
Previous therapy with abiraterone & $6.9(2)$ & 0 & 29.4 \\
acetate (\%) & & & 22.1 \\
Spread of disease (\%) & & 30.8 & 11.8 \\
Bone & 31 & 23 & \\
Lymph & 24.1 & 28.2 & \\
Bone and lymph & 37.9 & & \\
Visceral & 6.9 & & \\
\hline
\end{tabular}

Continuous values are presented as mean (IQR), Categorical values are presented in $N(\%)$
(26.1). Within patient variability was $8.8 \%$ for enzalutamide and $7.3 \%$ for $\mathrm{N}$-desmethylenzalutamide. Geometric mean levels for the sum, enzalutamide and N-desmethylenzalutamide were not different between the different age and BMI groups (Table 2). The median time to progression of the pooled data was 485 days (95\% CI 351-671). Time to progression analysis of quartiles of sum levels showed no difference in time to progression between the quartiles of exposure levels $(p=0.72)$, Fig. 2 b.

Five out of 29 patients in the ANDROPS study were excluded for the fatigue analysis: 2 due to clinical anemia for which they were treated, 1 used concomitant methylphenidate, another patient used concomitantly nilutamide, and 1 patient developed an aggressive second primary cancer. Fatigue was observed in 22 patients (36\%) (14 ANDROPS +8 ILUMINATE). For patients with fatigue, the median time to sample collection was 88 days (range 41-176) for patients in the ANDROPS study and in the ILUMINATE study, PK levels and fatigue reports at 3 months from start were included.

No difference in number of patients with fatigue was observed when quartiles of the enzalutamide $(p=0.53)$ and N-desmethylenzalutamide levels $(p=0.13)$ were analyzed by ANOVA. No statistical difference in sum levels, enzalutamide levels alone and N-desmethylenzalutamide levels alone were observed between patients who developed fatigue compared to those who did not develop fatigue (Table 3 ). The decrease in PSA after 12 weeks was comparable between patients with reported fatigue vs. patients without reported fatigue.

\section{Discussion}

The aim of this study was to evaluate the influence of age and BMI on enzalutamide and N-desmethylenzalutamide exposure and furthermore, to evaluate the relation between exposure and response and exposure and toxicity (fatigue) in $\mathrm{mCRPC}$ patients. No exposure-fatigue relationship, or exposure-response relationship was observed. Both age and BMI did not influence exposure to enzalutamide and $\mathrm{N}$-desmethylenzalutamide. Therefore, we conclude that no dose adjustments are needed based on age or BMI.

Plasma levels in our population were comparable to the PREVAIL data, suggesting comparable exposure in patients outside of clinical trials [19]. Age did not influence the exposure of enzalutamide and N-desmethylenzalutamide which is in line with recently published data by Crombag et al. describing that the exposure of enzalutamide and its metabolites was not influenced by age [13]. Finally, no influence of BMI on the exposure was shown in this study. However, only a small number of patients with high BMI (>30) were 
Fig. 2 a Time to progression for both treatment groups, $\mathbf{b}$ Time to progression compared between quartiles of sum levels. Quartile 1: 17.6-23.0 mg/L, quartile $2: 23.1-25.4 \mathrm{mg} / \mathrm{L}$, quartile $3: 25.5-29.1 \mathrm{mg} / \mathrm{L}$, quartile $4: 29.6-37.6 \mathrm{mg} / \mathrm{L}$
A Time to progression for both treatment groups

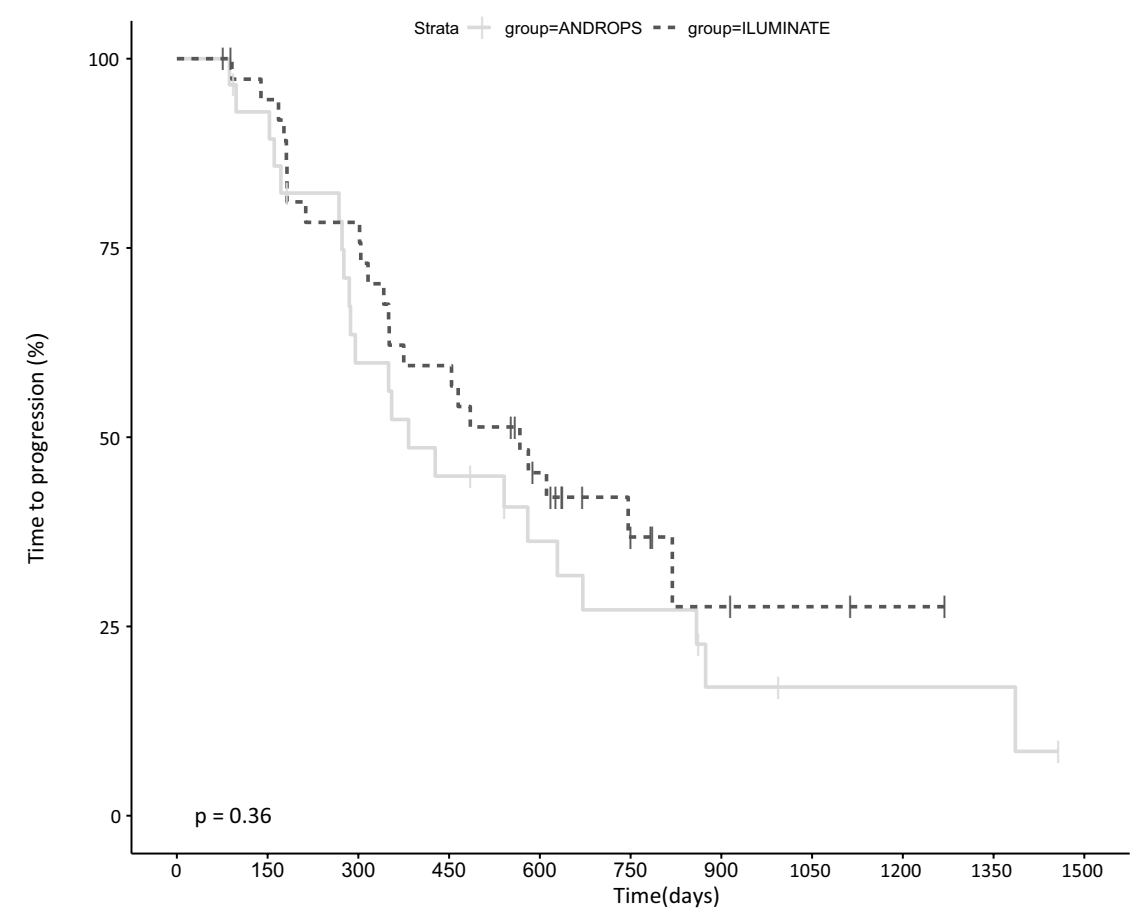
Number at risk

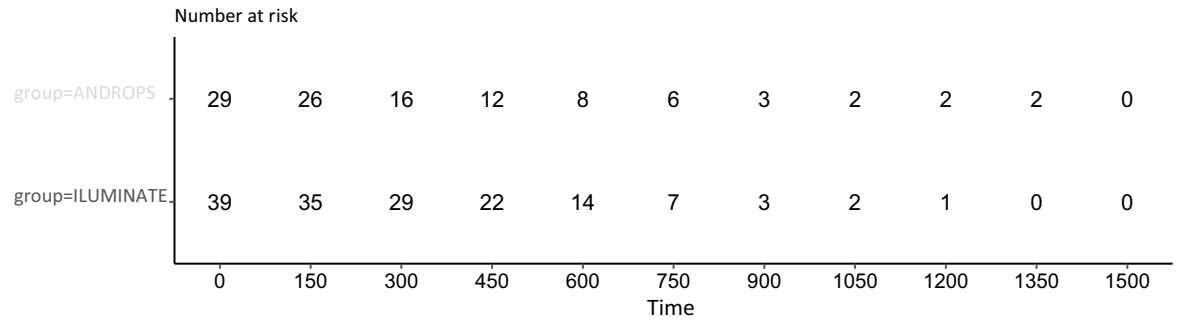

B Time to progression compared between quartiles of the sum levels
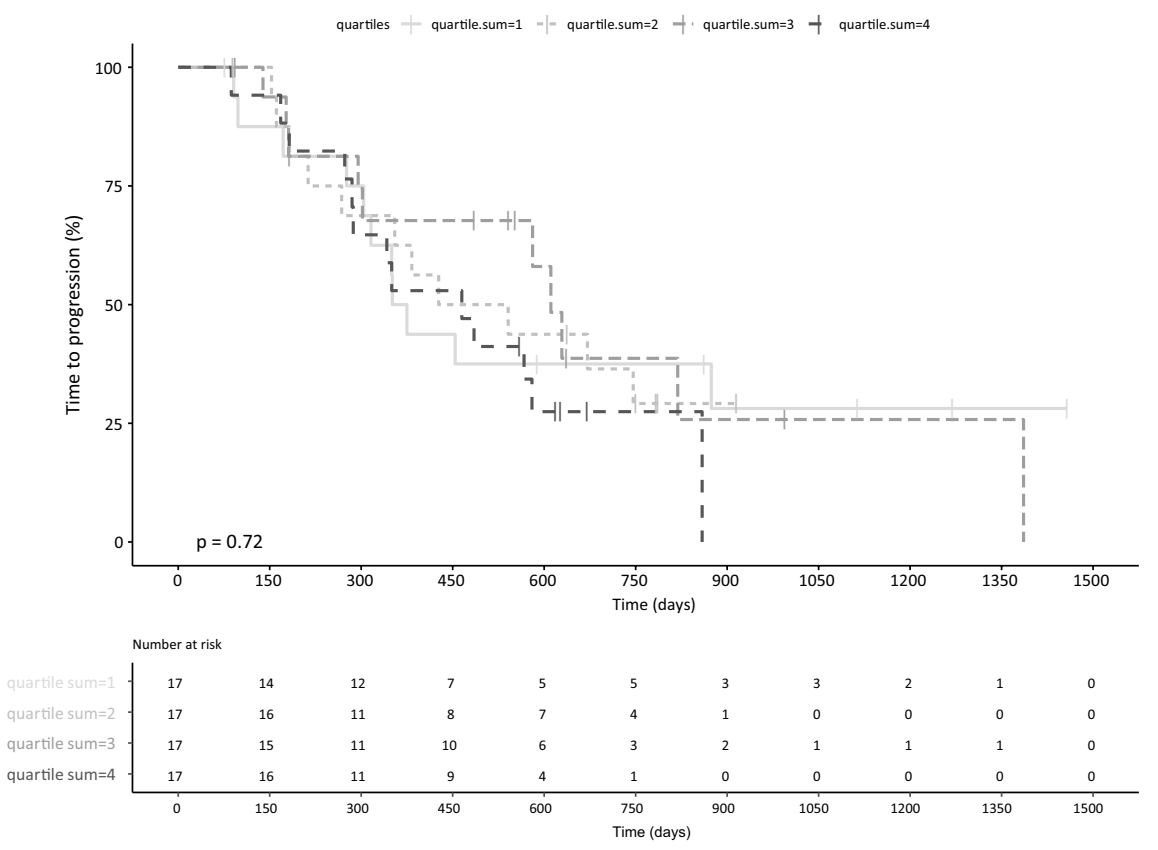
Table 2 Enzalutamide and N-desmethylenzalutamide levels related to age and body mass index (BMI)

\begin{tabular}{|c|c|c|c|c|c|c|c|c|}
\hline & \multicolumn{4}{|c|}{ Age category: median age (year) } & \multicolumn{4}{|c|}{ BMI mg/m² (category) } \\
\hline & $\begin{array}{l}\text { I: } 61 \\
N=23\end{array}$ & $\begin{array}{l}\text { II: } 73 \\
N=23\end{array}$ & $\begin{array}{l}\text { III: } 78 \\
N=22\end{array}$ & $P$ value & $\begin{array}{l}<25 \\
N=17\end{array}$ & $\begin{array}{l}25-30 \\
N=36\end{array}$ & $\begin{array}{l}>30 \\
N=14\end{array}$ & $P$ value \\
\hline Enzalutamide $(\mathrm{mg} / \mathrm{L})$; geometric mean $(\mathrm{CV} \%)$ & $12.5(21.3)$ & $13.2(21.4)$ & $12.2(18.8)$ & 0.78 & $12.2(20.1)$ & $12.6(17.9)$ & $13.2(27.4)$ & 0.31 \\
\hline $\begin{array}{l}\mathrm{N} \text {-desmethylenzalutamide }(\mathrm{mg} / \mathrm{L}) \text {; geometric } \\
\text { mean }(\mathrm{CV} \%)\end{array}$ & $12.5(25.9)$ & $13.6(26.9)$ & $14.1(25.4)$ & 0.15 & $14.4(30.4)$ & $13.4(23.6)$ & $12.4(25.9)$ & 0.11 \\
\hline
\end{tabular}

One-way ANOVA on geometric mean levels. Analysis performed on pooled data from ANDROPS and ILUMINATE. For one patient BMI was missing (ILUMINATE study)

Table 3 Patient characteristics and pharmacokinetics vs. occurrence of fatigue

\begin{tabular}{|c|c|c|c|}
\hline & \multicolumn{2}{|l|}{ Fatigue } & \multirow[b]{2}{*}{$P$ value } \\
\hline & Yes $(n=24)$ & No $(n=44)$ & \\
\hline Enzalutamide (mg/L) & $12.1(17.9)$ & $12.9(21.6)$ & 0.21 \\
\hline $\begin{array}{l}\text { N-desmethylenzalutamide } \\
(\mathrm{mg} / \mathrm{L})\end{array}$ & $13.9(26.9)$ & $13.2(25.7)$ & 0.43 \\
\hline $\begin{array}{l}\text { Sum of enzalutamide and N-des- } \\
\text { methylenzalutamide (mg/L) }\end{array}$ & $26.0(16.4)$ & $26.0(16.8)$ & 0.95 \\
\hline Age (years) & $71(31)$ & $73(8)$ & 0.18 \\
\hline $\begin{array}{l}\text { Hb level at time of sampling } \\
(\mathrm{mmol} / \mathrm{L})\end{array}$ & $8.2(1.4)$ & $8(0.8)$ & 0.32 \\
\hline Albumin (g/L) & $37(5)$ & $38(6)$ & 0.42 \\
\hline Previous chemotherapy & $7(29.2)$ & $8(18.2)$ & 0.30 \\
\hline Opioid comedication & $4(16.7)$ & $6(13.6)$ & - \\
\hline Sedative comedication ${ }^{\mathrm{a}}$ & $5(20.8)$ & $2(4.5)$ & - \\
\hline $\begin{array}{l}\text { Median PSA decrease at } 12 \\
\text { wks } \%\end{array}$ & $-82.3(34)$ & $-77.5(28)$ & - \\
\hline
\end{tabular}

Concentration levels are described as mean with $\mathrm{CV} \%$, continuous variables as median (IQR), categorical variables as $N(\%)$

${ }^{\text {a Benzodiazepines }}$

included and, therefore, these results should be treated with caution and cannot be extrapolated to morbid obese patients treated with enzalutamide. In our study population, median age and BMI were comparable to the populations of the prevail and affirm trials $[5,6]$.

Furthermore, longitudinal exposure was evaluated in a clinical setting and observed very low within patient variability of both enzalutamide and N-desmethylenzalutamide $(<10 \%)$ at steady state. This is lower than the data shown in the population pharmacokinetic analysis [15]. This finding might be explained by a lower number of samples per patient in our study in comparison to previous data, although variability observed was also low $(<30 \%)$ in the population pharmacokinetic analysis [15]. The low intrasubject variability adds value for individual patients, since a single measurement of plasma concentrations after a dose reduction can provide information on exposure levels during treatment.
Data on fatigue in our study were spontaneously reported by patients (yes/no) and no formal questionnaires such as FACIT-fatigue were used. Also, scoring of fatigue was performed by yes/no answers, therefore, differences in the extent of this side effect may have been missed; which could have led to reporting bias. Furthermore, fatigue is known as a multidimensional symptom and can be influenced by several aspects such as exercising, comorbidities, previous medications and pain. Since these data were not collected, this analysis was not controlled for these effects. However, the prevalence of fatigue in our study (36\%) is corresponding to previously published data [3]. Failure of treatment could be of influence on the reporting of fatigue since cancer progression can lead to fatigue. However, in patients with and without fatigue, the decrease in PSA was not different, suggesting that no effect from (biochemical) treatment response on the occurrence of fatigue was suggested. In addition, to reduce potential bias of treatment failure on the reported fatigue, a time frame of the first 6 months since start of treatment was used. The recent AQUARiUS study showed a significant difference from baseline for fatigue level after 3 months of enzalutamide therapy compared to abiraterone, supporting the time frame selected for analysis in our study [20].

No relation between fatigue and the plasma levels of enzalutamide, $\mathrm{N}$-desmethylenzalutamide or the sum, was observed. This may be explained by the hypothesis that with the current dose, both the plateau of the exposure-response curve and the exposure-toxicity curve are reached and no additional toxicity nor efficacy is observed when the exposure increases [19, 21]. Furthermore, due to previously mentioned drawbacks in the evaluation of fatigue, we cannot exclude that patients with severe fatigue are overexposed to enzalutamide. Also, the limited intersubject variability in exposure may hamper the analysis of a pharmacokinetic-pharmacodynamic relation at this dose level. An implication hereof might be that an exposure-toxicity relationship should be evaluated over a broader dose range, including a lower dose, for which a randomized study is currently ongoing (NCT03927391). 
Concluding, we investigated the influence of patient characteristics on enzalutamide and $\mathrm{N}$-desmethylenzalutamide levels in mCRPC patients, and observed that age and BMI did not influence systemic exposure. Further structured prospective research is needed to understand the relation between exposure and fatigue, as knowledge on this subject can help clinicians and patients in management of this burdening side effect.

Acknowledgements This study was part of the REFINE project (grant no. 836041013) that is funded by ZonMw, The Netherlands Organisation for Health Research and development, as part of the GGG program and supported by a research grant of Astellas Pharma BV.

\section{Compliance with ethical standards}

Conflict of interest Dr. van Erp reports grants from ZonMW, during the conduct of the study; grants from Astellas, grants from JanssenCilag, outside the submitted work; Dr. van Oort reports grants from ZonMw, during the conduct of the study; personal fees and other from Astellas, personal fees and other from Janssen, outside the submitted work; Dr Mehra reports personal fees from Roche, MSD, BMS, Bayer, Astellas and Janssen', grants from Astellas, Janssen Pfizer, Roche and Sanofi' Genzyme, work and other from Astellas and MSD, outside the submitted work. The other authors have nothing to disclose.

Open Access This article is licensed under a Creative Commons Attribution 4.0 International License, which permits use, sharing, adaptation, distribution and reproduction in any medium or format, as long as you give appropriate credit to the original author(s) and the source, provide a link to the Creative Commons licence, and indicate if changes were made. The images or other third party material in this article are included in the article's Creative Commons licence, unless indicated otherwise in a credit line to the material. If material is not included in the article's Creative Commons licence and your intended use is not permitted by statutory regulation or exceeds the permitted use, you will need to obtain permission directly from the copyright holder. To view a copy of this licence, visit http://creativecommons.org/licenses/by/4.0/.

\section{References}

1. Bray F, Ferlay J, Soerjomataram I, Siegel RL, Torre LA, Jemal A (2018) Global cancer statistics 2018: GLOBOCAN estimates of incidence and mortality worldwide for 36 cancers in 185 countries. CA 68(6):394-424

2. Tannock IF, de Wit R, Berry WR, Horti J, Pluzanska A, Chi KN, Oudard S, Theodore C, James ND, Turesson I, Rosenthal MA, Eisenberger MA, TAX Investigators (2004) Docetaxel plus prednisone or mitoxantrone plus prednisone for advanced prostate cancer. N Engl J Med 351(15):1502-1512. https://doi.org/10.1056/ NEJMoa040720

3. Beer TM, Armstrong AJ, Rathkopf D, Loriot Y, Sternberg CN, Higano CS, Iversen P, Evans CP, Kim CS, Kimura G, Miller K, Saad F, Bjartell AS, Borre M, Mulders P, Tammela TL, Parli T, Sari S, van Os S, Theeuwes A, Tombal B (2017) Enzalutamide in men with chemotherapy-naive metastatic castration-resistant prostate cancer: extended analysis of the phase 3 prevail study. Eur Urol 71(2):151-154. https://doi.org/10.1016/j.eururo.2016.07.032
4. Berthold DR, Pond GR, Roessner M, de Wit R, Eisenberger M, Tannock AI, Investigators TAX (2008) Treatment of hormonerefractory prostate cancer with docetaxel or mitoxantrone: relationships between prostate-specific antigen, pain, and quality of life response and survival in the TAX-327 study. Clin Cancer Res 14(9):2763-2767. https://doi.org/10.1158/1078-0432. CCR-07-0944

5. Scher HI, Fizazi K, Saad F, Taplin ME, Sternberg CN, Miller K, de Wit R, Mulders P, Chi KN, Shore ND, Armstrong AJ, Flaig TW, Flechon A, Mainwaring P, Fleming M, Hainsworth JD, Hirmand M, Selby B, Seely L, de Bono JS, Investigators A (2012) Increased survival with enzalutamide in prostate cancer after chemotherapy. N Engl J Med 367(13):1187-1197. https://doi. org/10.1056/NEJMoa1207506

6. Beer TM, Armstrong AJ, Rathkopf DE, Loriot Y, Sternberg CN, Higano CS, Iversen P, Bhattacharya S, Carles J, Chowdhury S, Davis ID, de Bono JS, Evans CP, Fizazi K, Joshua AM, Kim CS, Kimura G, Mainwaring P, Mansbach H, Miller K, Noonberg SB, Perabo F, Phung D, Saad F, Scher HI, Taplin ME, Venner PM, Tombal B, The PI (2014) Enzalutamide in metastatic prostate cancer before chemotherapy. N Engl J Med 371(5):424-433. https ://doi.org/10.1056/NEJMoa1405095

7. de Bono JS, Logothetis CJ, Molina A, Fizazi K, North S, Chu L, Chi KN, Jones RJ, Goodman OB Jr, Saad F, Staffurth JN, Mainwaring P, Harland S, Flaig TW, Hutson TE, Cheng T, Patterson H, Hainsworth JD, Ryan CJ, Sternberg CN, Ellard SL, Flechon A, Saleh M, Scholz M, Efstathiou E, Zivi A, Bianchini D, Loriot Y, Chieffo N, Kheoh T, Haqq CM, Scher HI (2011) Abiraterone and increased survival in metastatic prostate cancer. N Engl J Med 364(21):1995-2005. https://doi.org/10.1056/NEJMoa1014618

8. Hussain M, Fizazi K, Saad F, Rathenborg P, Shore N, Ferreira U, Ivashchenko P, Demirhan E, Modelska K, Phung KA, Sternberg CN (2018) Enzalutamide in men with nonmetastatic, castrationresistant prostate cancer. N Engl J Med 378(26):2465-2474. https ://doi.org/10.1056/NEJMoa1800536

9. EMA (2019) European Public Assessment Report (EPAR) Xtandi (enzalutamide). EMA, Amsterdam

10. Davis ID, Martin AJ, Stockler MR, Begbie S, Chi KN, Chowdhury S, Coskinas X, Frydenberg M, Hague WE, Horvath LG, Joshua AM, Lawrence NJ, Marx G, McCaffrey J, McDermott R, McJannett M, North SA, Parnis F, Parulekar W, Pook DW, Reaume MN, Sandhu SK, Tan A, Tan TH, Thomson A, Tu E, Badillo F, Williams SG, Yip S, Zhang AY, Zielinski RR, Sweeney CJ (2019) Enzalutamide with standard first-line therapy in metastatic prostate cancer. N Engl J Med. https://doi.org/10.1056/NEJMoa1903 835

11. Le Couteur DG, McLean AJ (1998) The aging liver. Clin Pharmacokinet 34(5):359-373. https://doi.org/10.2165/00003088-19983 4050-00003

12. Westgeest HM, -de Groot CA, van Moorselaar RJA, de Wit R, van den Bergh ACM, Coenen J, Beerlage HP, Hendriks MP, Bos M, van den Berg P, van de Wouw AJ, Spermon R, Boerma MO, Geenen MM, Tick LW, Polee MB, Bloemendal HJ, Cordia I, Peters FPJ, de Vos AI, van den Bosch J, van den Eertwegh AJM, Gerritsen WR (2018) Differences in trial and real-world populations in the dutch castration-resistant prostate cancer registry. Eur Urol Focus 4(5):694-701. https://doi.org/10.1016/j. euf.2016.09.008

13. Crombag MBS, van Nuland M, Bergman AM, Rosing H, Schellens JHM, Huitema ADR, Beijnen JH (2019) Impact of age on exposure to oral antiandrogen therapies in clinical practice. Prostate Cancer Prostatic Dis 22(1):168-175. https://doi.org/10.1038/ s41391-018-0096-z

14. Foster WR, Car BD, Shi H, Levesque PC, Obermeier MT, Gan J, Arezzo JC, Powlin SS, Dinchuk JE, Balog A, Salvati ME, Attar 
RM, Gottardis MM (2011) Drug safety is a barrier to the discovery and development of new androgen receptor antagonists. Prostate 71(5):480-488. https://doi.org/10.1002/pros.21263

15. FDA (2012) US Food and Drug Administration. Clinical pharmacology and biopharmaceutics review Xtandi (Enzalutamide). FDA, Silver Spring, pp 1-83

16. Scher HI, Beer TM, Higano CS, Anand A, Taplin ME, Efstathiou E, Rathkopf D, Shelkey J, Yu EY, Alumkal J, Hung D, Hirmand M, Seely L, Morris MJ, Danila DC, Humm J, Larson S, Fleisher M, Sawyers CL, Prostate Cancer Foundation/Department of Defense Prostate Cancer Clinical Trials C (2010) Antitumour activity of MDV3100 in castration-resistant prostate cancer: a phase 1-2 study. Lancet 375(9724):1437-1446. https://doi. org/10.1016/S0140-6736(10)60172-9

17. Eliasson L, de Freitas HM, Dearden L, Calimlim B, Lloyd AJ (2017) Patients' preferences for the treatment of metastatic castrate-resistant prostate cancer: a discrete choice experiment. Clin Ther 39(4):723-737. https://doi.org/10.1016/j.clint hera.2017.02.009

18. Benoist GE, van der Meulen E, van Oort IM, Beumer JH, Somford DM, Schalken JA, Burger DM, van Erp NP (2018) Development and validation of a bioanalytical method to quantitate enzalutamide and its active metabolite $\mathrm{n}$-desmethylenzalutamide in human plasma: application to clinical management of patients with metastatic castration-resistant prostate cancer. Ther Drug Monit 40(2):222-229. https://doi.org/10.1097/ftd.0000000000 000484

19. Gibbons JA, Ouatas T, Krauwinkel W, Ohtsu Y, van der Walt JS, Beddo V, de Vries M, Mordenti J (2015) Clinical pharmacokinetic studies of enzalutamide. Clin Pharmacokinet 54(10):1043-1055. https://doi.org/10.1007/s40262-015-0271-5

20. Thiery-Vuillemin A, Poulsen MH, Lagneau E, Ploussard G, Birtle A, Dourthe LM, Ardisson D, Pintus E, Trepiakas R, Antoni L, Lukac M, Van Sanden S, Pissart G, Reid A (2018) Impact of abiraterone acetate plus prednisone or enzalutamide on fatigue and cognition in patients with metastatic castration-resistant prostate cancer: initial results from the observational AQUARiUS study. ESMO Open 3(5):e000397. https://doi.org/10.1136/esmoopen2018-000397

21. FDA (2012) US food and drug administration. Pharmacology review Xtandi (Enzalutamide). FDA, Sliver Spring

Publisher's Note Springer Nature remains neutral with regard to jurisdictional claims in published maps and institutional affiliations. 